\title{
Synthesis and characterization of novel thienyl-pyridazine derivatives
}

Sara S. M. Fernandes and M. Manuela M. Raposo*

\author{
Centre of Chemistry, University of Minho, Campus de Gualtar, 4710-057, Braga, Portugal \\ Email: mfox@quimica.uminho.pt
}

\begin{abstract}
We report the synthesis and the photophysical characterization of novel thienylpyridazine derivatives, functionalized in position 3, with different donor groups (thiophene, pyrrole and $\mathrm{N}, \mathrm{N}$-dialkylphenylamine). The diazines were synthesized by Suzuki coupling of 3bromo-6-(thiophen-2-yl)pyridazine with commercially available (hetero)aryl-boronic acids in fair to good yields. On the other hand, precursor 3-bromo-6-(thiophen-2-yl)pyridazine was prepared by reaction of a thienyl-pyridazinone with $\mathrm{POBr}_{3}$.
\end{abstract}

Keywords: Push-pull $\pi$-conjugated compounds, pyridazines, thiophene, pyrrole, Suzuki crosscoupling reaction 


\section{Introduction}

Recently, the exploration of dipolar chromophores has greatly expanded due to the increased interest in nonlinear optics (NLO), organic light emitting diodes (OLEDs) and dye sensitizers solar cell (DSSCs) applications. This type of molecules are highly targeted due to the easy tuning of the photophysical properties by small structural modifications. ${ }^{[1-7]}$ The electronic arrangement of these compounds is based in an electron donor group linked to an electron acceptor group through a $\pi$-conjugated bridge, which leads to an efficient intramolecular charge transfer. Recent advances consists on the design of systems bearing heterocyclic $\pi$-bridges and/or the use of an electron rich or electron deficient heterocycle that acts as an adjuvant electron donor or acceptor group. ${ }^{[2]}$

Several thienyl-pyridazine and thienyl-phthalazine derivatives were synthesized and characterized as part of an on-going research directed to the development of donor-acceptor substituted heterocyclic systems for NLO and DSSCs applications. ${ }^{[8-11]}$

In this communication, we report the synthesis and the photophysical characterization of novel thienyl-pyridazine derivatives 3-5, functionalized in position 3, with different donor groups (thiophene, pyrrole and $\mathrm{N}, \mathrm{N}$-dialkylphenylamine). The diazines were synthesized by Suzuki coupling of 3-bromo-6-(thiophen-2-yl)pyridazine with commercially available (hetero)aryl-boronic acids in fair to good yields. On the other hand, precursor 3-bromo-6-(thiophen-2-yl)pyridazine was prepared by reaction of a thienyl-pyridazinone with $\mathrm{POBr}_{3}$.

Photophysical study of compounds 3-5, shows the influence of the electronic nature of the (hetero)aryl group linked to the pyridazine moiety on the optical properties of $\pi$-conjugated systems as well as their potential application for nonlinear optics (NLO).

\section{Experimental}

\section{a. Instruments}

NMR spectra were obtained on a Varian Unity Plus Spectrometer at an operating frequency of 300 $\mathrm{MHz}$ for ${ }^{1} \mathrm{H}$ NMR and $75.4 \mathrm{MHz}$ for ${ }^{13} \mathrm{C}$ NMR or a Brucker Avance III 400 at an operating frequency of $400 \mathrm{MHz}$ for ${ }^{1} \mathrm{H}$ NMR and $100.6 \mathrm{MHz}$ for ${ }^{13} \mathrm{C}$ NMR using the solvent peak as internal reference at $25 \stackrel{\circ}{\circ}$ ( $\delta$ relative to TMS). All chemical shifts are given in $\mathrm{Hz}$. Assignments were made by comparison of chemical shift, peak multiplicities and $J$ values and were supported by spin decoupling-double resonance and bidimensional heteronuclear HMBC and HMQC correlation techniques. IR spectra were determined on a BOMEM MB 104 spectrophotometer. UV-Visible absorption spectra (200-800 nm) were obtained using a Shimadzu UV/2501PC spectrophotometer. All melting points were measured on a Gallenkamp melting point apparatus and are uncorrected. 


\section{b. Material}

Phosphorous (V) oxybromide and boronic acids were purchased from Aldrich, Acros Organics and Fluka and used as received. TLC analyses were carried out on $0.25 \mathrm{~mm}$ thick precoated silica plates (Merck Fertigplatten Kieselgel $6 \mathrm{FF}_{254}$ ) and spots were visualized under UV light. Chromatography on silica gel was carried out on Merck Kieselgel (200-300 mesh).

\section{c. Synthesis}

The procedure for the synthesis of 3-bromo-6-(thiophene-2-yl)pyridazine 2 was described elsewhere. ${ }^{[10]}$

General procedure for the synthesis of thienyl-pyridazine derivatives 3-5 through Suzuki coupling:

3-bromo-6-(thiophene-2-yl)pyridazine $2(0.5 \mathrm{mmol}, 120 \mathrm{mg}$ ) was coupled to (hetero)arylboronic acids $(0.6 \mathrm{mmol})$ in a mixture of DME $(8 \mathrm{~mL})$, ethanol $(2 \mathrm{~mL})$, aqueous $2 \mathrm{M} \mathrm{Na}_{2} \mathrm{CO}_{3}(1 \mathrm{ml})$ and $\mathrm{Pd}\left(\mathrm{PPh}_{3}\right)_{4}(5 \mathrm{~mol} \%)$ at $80^{\circ} \mathrm{C}$ under nitrogen. The reaction was monitored by TLC, which determined the reaction time (24-32 h). After cooling, the mixture was extracted with chloroform $(3 \times 20 \mathrm{ml})$ and a saturated solution of $\mathrm{NaCl}$ were added $(20 \mathrm{~mL})$ and the phases were separated. The organic phase was washed with water $(3 \times 10 \mathrm{~mL})$ and with $10 \mathrm{~mL}$ of a solution of $\mathrm{NaOH}(10 \%)$. The organic phase obtained was dried $\left(\mathrm{MgSO}_{4}\right)$, filtered, and the solvent removed to give a crude mixture. The crude product was purified through a silica gel chromatography column using mixtures of chloroform and light petroleum of increasing polarity to afford the coupled products 3-5. Recrystallization from $n$-hexane / dichloromethane gave the pure compounds.

3,6-Di(thiophen-2'-yl)pyridazine 3. Yellow solid (45\%). Mp: 181-183ㄷ. UV (chloroform): $\lambda_{\max } \mathrm{nm}$ $\left(\varepsilon, \mathrm{M}^{-1} \mathrm{~cm}^{-1}\right) 337(36,140)$. IR (liquid film) v 3410, 2108, 1640, 1546, 1434, 1337, 1230, 1118, 1055, $850,832,737,713 \mathrm{~cm}^{-1} .{ }^{1} \mathrm{H}$ NMR (DMSO-d $6,300 \mathrm{MHz}$ ) $\delta 7.23$ (dd, $2 \mathrm{H}, 2 \times \mathrm{H}-4^{\prime}, J=4.8 \mathrm{~Hz}, \mathrm{~J}=3.6 \mathrm{~Hz}$ ), 7.75 (dd, $2 \mathrm{H}, 2 \times \mathrm{H}-5^{\prime}, \mathrm{J}=5.2 \mathrm{~Hz}, \mathrm{~J}=0.8 \mathrm{~Hz}$ ), 7.95 (dd, $2 \mathrm{H}, 2 \times \mathrm{H}-3^{\prime}, \mathrm{J}=3.8 \mathrm{~Hz}, \mathrm{~J}=1.2 \mathrm{~Hz}$ ), 8.25 (br s, $2 \mathrm{H}$, $\mathrm{H}-4$ and H-5) ppm. ${ }^{13} \mathrm{C}$ NMR (DMSO-d 6 , $300 \mathrm{MHz}$ ) $\delta 123.17$ (C-4 and C-5), 127.43 (C-3'), 128.50 (C$\left.4^{\prime}\right), 129.80$ (C-5'), 140.23 (C-2'), 153.26 (C-3 and C-6) ppm.

3-(1'-Methyl-1H-pyrrol-2'-yl)-6-(thiophen-2"'-yl)pyridazine 4. Yellow oil (20\%). UV (chloroform): $\lambda_{\max } \mathrm{nm}\left(\varepsilon, \mathrm{M}^{-1} \mathrm{~cm}^{-1}\right) 342(23,820)$. IR (liquid film) $v 3426,2088,1640,1555,1483,1434,1311,1121$, 1066, 1031, $831 \mathrm{~cm}^{-1} .{ }^{1} \mathrm{H}$ NMR (DMSO-d $6,300 \mathrm{MHz}$ ) $\delta 4.02\left(\mathrm{~s}, 3 \mathrm{H}, \mathrm{CH}_{3}\right), 6.16$ (dd, $1 \mathrm{H}, \mathrm{H}-4^{\prime}, \mathrm{J}=3.9 \mathrm{~Hz}$, $J=2.7 \mathrm{~Hz}$ ), 6.85 (dd, 1H, H-3', J=3.6 Hz, J=1.8 Hz), 7.01 (t, 1H, H-5', J=2.4 Hz), 7.21 (dd, $1 \mathrm{H}, \mathrm{H}-4^{\prime \prime}$, $J=5.1 \mathrm{~Hz}, J=3.9 \mathrm{~Hz}$ ), 7.72 (dd, $1 \mathrm{H}, \mathrm{H}-5^{\prime \prime}, J=5.1 \mathrm{~Hz}, J=0.9 \mathrm{~Hz}$ ), 7.90 (dd, $1 \mathrm{H}, \mathrm{H}-3^{\prime \prime}, J=3.6 \mathrm{~Hz}, J=0.9 \mathrm{~Hz}$ ), $7.95\left(\mathrm{~d}, 1 \mathrm{H}, \mathrm{H}-4, J=9.0 \mathrm{~Hz}\right.$ ), $8.14\left(\mathrm{~d}, 1 \mathrm{H}, \mathrm{H}-5, J=9.3 \mathrm{~Hz}\right.$ ) ppm. ${ }^{13} \mathrm{C}$ NMR (DMSO-d, $300 \mathrm{MHz}$ ) $\delta 37.63$ $\left(\mathrm{CH}_{3}\right), 108.11$ (C-4'), 112.95 (C-3'), 122.89 (C-5), 124.97 (C-4), 126.86 (C-3'), 128.24 (C-2'), 128.39 (C-4"), 128.61 (C-5"), 129.31 (C-5'), 140.61 (C-2'), 151.47 (C-6), 152.93 (C-3) ppm.

$N, N$-Dimethyl-4-(6'-(thiophen-2"'-yl)pyridazin-3'-yl)aniline 5. Yellow solid (31\%). UV (chloroform): $\lambda_{\max } \mathrm{nm}\left(\varepsilon, \mathrm{M}^{-1} \mathrm{~cm}^{-1}\right) 368(19,550)$. IR (liquid film) $\vee 2923,1611,1580,1527,1439,1405,1366,1302$, 
1228, 1195, 1127, 1062, 852, 815, $702 \mathrm{~cm}^{-1} .{ }^{1} \mathrm{H}$ NMR (DMSO-d $\left.6,400 \mathrm{MHz}\right) \delta 3.00\left(\mathrm{~s}, 6 \mathrm{H}, 2 \times \underline{H}_{3}\right.$ ), $6.84\left(\mathrm{~d}, 2 \mathrm{H}, \mathrm{H}-3\right.$ and H-5, J=9.2 Hz), 7.22 (dd, $1 \mathrm{H}, \mathrm{H}-4^{\prime \prime}$, J=4.8 Hz, J=3.6 Hz), 7.70 (dd, $1 \mathrm{H}, \mathrm{H}-5^{\prime \prime}, \mathrm{J}=5.0$ $\mathrm{Hz}, J=1.2 \mathrm{~Hz}$ ), 7.90 (dd, $1 \mathrm{H}, \mathrm{H}-3^{\prime \prime}, J=3.6 \mathrm{~Hz}, J=1.2 \mathrm{~Hz}$ ), 8.05 (d, 2H, H-2 and H-6, J=9.2 Hz), 8.11 (d, $1 \mathrm{H}, \mathrm{H}-4^{\prime}, J=9.2 \mathrm{~Hz}$ ), $8.16\left(\mathrm{~d}, 1 \mathrm{H}, \mathrm{H}-5^{\prime}, J=9.2 \mathrm{~Hz}\right.$ ) ppm. ${ }^{13} \mathrm{C}$ NMR (Acetona-d $\left.6,400 \mathrm{MHz}\right) \delta 40.24$ $\left(2 \times \mathrm{CH}_{3}\right), 112.96$ (C-2 and C-6), 123.22 (C-4' or C-5'), 123.29 (C-4' or C-5'), 124.39 (C-4), 126.61 (C$\left.3^{\prime \prime}\right), 128.39$ (C-3 and C-5), 128.91 (C-4"), 129.31 (C-5"), 142.46 (C-2"), 152.77 (C-1), 153.32 (C-6'), $158.27\left(\mathrm{C}-3^{\prime}\right) \mathrm{ppm}$.

\section{Results and Discussion}

\section{a. Synthesis}

The precursor bromo-thienylpyridazine $\mathbf{2}$ was synthesized by reaction of thienyl-pyridazinone $\mathbf{1}$ with $\mathrm{POBr}_{3}$, which was previously prepared by condensation of methyl 4-oxo-4-(thiophen-2yl)butanoate with hydrazine hydrate in ethanol. ${ }^{[10]}$ Compounds 3-5 were obtained from Suzuki cross-coupling reaction of 3-bromo-6-(thiophen-2-yl)pyridazine 2 with commercially available (hetero)aryl-boronic acids in fair to good yields (20-45 \%) (Table 1, Scheme 1 ). The new heterocyclic systems 3-5 were characterized by the usual spectroscopic techniques.

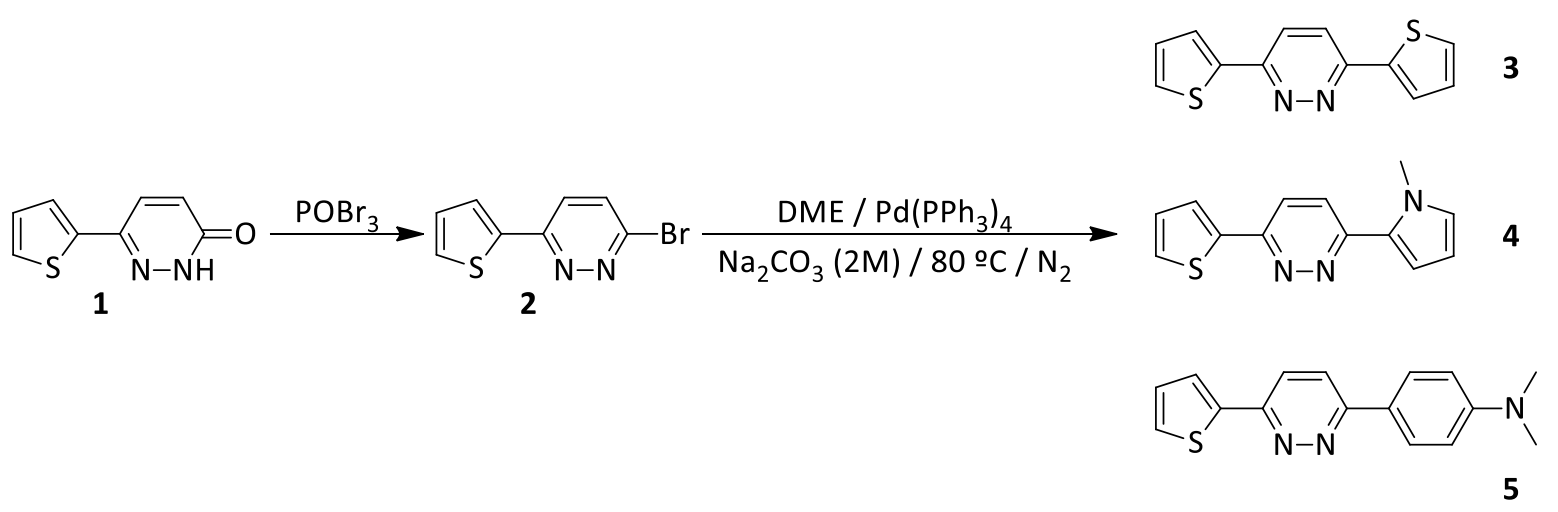

Scheme 1. Synthesis of thienyl-pyridazine derivatives 2-5.

\section{b. Results}

All chromophores exhibit broad and intense intra-molecular charge transfer (ICT) absorptions in the visible region from $337 \mathrm{~nm}$ to $368 \mathrm{~nm}$ in chloroform solutions $\left(10^{-4} \mathrm{M}\right)$. The position of this band is strongly influenced by the electronic nature of the donor moiety linked to the piridazine heterocycle. As observed earlier for other push-pull systems, a bathochromic shift in the UV-vis. spectra is detected when stronger donor groups are linked to the heterocyclic system. ${ }^{[11]}$ Therefore, the substitution of thiophene (3) by pyrrole (4) or by $N, N$-dimethylamino- (5) groups in the thienyl-piridazine system results in bathochromic shifts $(7-31 \mathrm{~nm})$ in the UV-Vis. spectra due 
to the stronger electron-donating ability of pyrrole and $\mathrm{N}, \mathrm{N}$-dimethylamino- group compared to the thiophene heterocycle (Figure 1, Table 1).

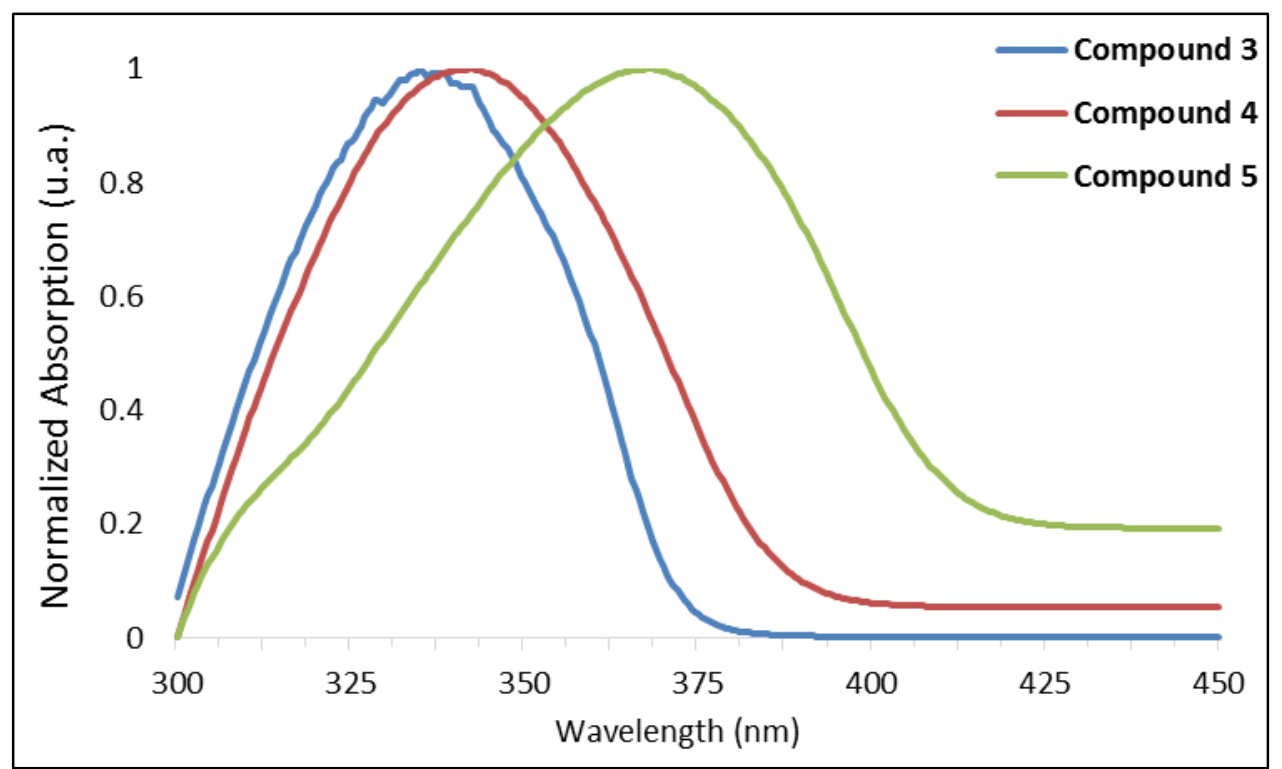

Figure 1. UV-visible spectra of novel thienyl-pyridazine 3-5 in chloroform $\left(10^{-4} \mathrm{M}\right)$.

The ${ }^{1} \mathrm{H}$ NMR chemical shifts reflect a charge separation in the ground state, consequently the analysis of these data in donor-acceptor compounds such as thienyl-piridazines 3-5 bearing thiophene, pyrrole and $\mathrm{N}, \mathrm{N}$-dimethylamino- donor moieties (Table 1 ) also confirms their push-pull character with a significant intramolecular charge transfer (ICT) from the donor to the acceptor part of the molecule. This interpretation is supported by the observation of the chemical shifts of the protons in compounds $\mathbf{4}$ and $\mathbf{5}$ bearing stronger donor groups connected the thienyl-piridazine system, which exhibit signals that are upfield relative to the thiophene $\mathbf{3}$ indicating a more efficient ICT from the donor to the acceptor group.

Table 1. Yields, UV-visible and ${ }^{1} \mathrm{H}$ RMN data of thienyl-pyridazines 3-5.

\begin{tabular}{cccccccccc}
\hline \multirow{2}{*}{ Compound } & $\begin{array}{c}\text { Yield } \\
(\%)\end{array}$ & $\begin{array}{c}\lambda_{\max } \\
(\mathrm{nm})^{(\mathrm{a})}\end{array}$ & $\begin{array}{c}\boldsymbol{\varepsilon} \\
\left(\mathrm{M}^{-1} \mathrm{~cm}^{-1}\right)^{(\mathrm{a})}\end{array}$ & \multicolumn{2}{c}{$\boldsymbol{\delta}_{\mathrm{H}}$ (pyridazine ring) $(\mathrm{ppm})^{(\mathrm{b})}$} & \multicolumn{3}{c}{$\boldsymbol{\delta}_{\mathrm{H}}$ (thiophene ring) $(\mathrm{ppm})^{(\mathrm{b})}$} \\
\cline { 7 - 11 } & $\mathbf{3}$ & 45 & 337 & 36,140 & & $\mathrm{H}-5$ & $\mathrm{H}-3$ & $\mathrm{H}-4$ & $\mathrm{H}-5$ \\
$\mathbf{4}$ & 20 & 342 & 23,820 & 7.95 & & 8.14 & 7.95 & 7.23 & 7.75 \\
$\mathbf{5}$ & 31 & 368 & 19,550 & 8.11 & 8.16 & 7.90 & 7.22 & 7.70 \\
\hline
\end{tabular}

(a) All the UV-visible spectra were performed in chloroform.

(b) For the pyridazine protons of compounds 3-4 (DMSO- $\mathrm{d}_{6}, 300 \mathrm{MHz}$ ) and 5 (DMSO- $\mathrm{d}_{6}, 400 \mathrm{MHz}$ ). 


\section{Conclusion}

Three new thienyl-pyridazine derivatives 3-5 were synthesized in fair to good yields through Suzuki cross-coupling. By varying the electronic nature of the donor group linked to the thienyl-pyridazine system, the optical and electronic properties of compounds 3-5 can be readily tuned. Therefore, $\pi$-conjugated systems 3-5 are versatile precursors that could be used for the preparation of nonlinear optical (SHG, TPA), OLEDs and DSSCs materials.

\section{Acknowledgements}

Thank are due to Fundação para a Ciência e Tecnologia (Portugal) and FEDER-COMPETE for financial support through the Centro de Química PEst-C/QUI/UI0686/2011 (F-COMP-01-0124FEDER-022716) and a PhD grant to S. S. M. Fernandes (SFRH/BD/87786/2012). The NMR spectrometer Bruker Avance III 400 is part of the National NMR Network and was purchased within the framework of the National Program for Scientific Re-equipment, contract REDE/1517/RMN/2005 with funds from POCI 2010 (FEDER) and FCT. We are also grateful to the Instituto da Educação of Universidade do Minho for providing the laboratory infrastructure necessary for the development of this work.

\section{References:}

[1] Dalton, L. R.; Sullivan, P. A.; Bale, D. H.; Chem. Rev., 2010, 110, 25.

[2] Zhu, X. H.; Peng, J. B.; Cao, Y.; Roncali, J.; Chem. Soc. Rev., 2011, 40, 3509.

[3] Misha, A.; Fischer, M. K. R.; Bauerle, P.; Angew. Chem. Int. Ed., 2009, 48, 2479.

[4] Mishra, A.; Ma, C.-Q.; Baeuerle, P.; Chem. Rev., 2009, 109, 1141.

[5] Handbook of Thiophene-Based Materials: Applications in Organic electronics and Photonics; Perepichka, F., Perepichka, D. F., Ed.; Wiley: New York, 2009.

[6] Bäuerle, P.; The Synthesis of Oligothiophenes, In Handbook of Oligo- and Polythiophenes; Fichou, D., Ed.; Wiley-VCH: Weinheim, 1999; Cap. 3, p 89.

[7] Pina, J.; Mello, J. S.; Breusov, D; Scherf, U.; Phys. Chem. Chem. Phys., 2013, 15, 15204.

[8] Raposo, M. M. M.; Sampaio, A. M. B. A.; Kirsch, G.; J. Heterocyclic Chem., 2005, 42, 1245.

[9] Vieira, L. M. C.; Fonseca, A. M.; Raposo, M. M. M., Kirsch, G., Portugaliae Electrochimica Acta, 2004, 22, 11.

[10] Fernandes, S. S. M.; Raposo, M. M. M.; Proceedings of the 17th Int. Electron. Conf. Synth. Org. Chem., 1-30 November 2013; Sciforum Electronic Conference Series, 2013, 17, a038.

[11] Fernandes, S. S. M.; Raposo, M. M. M.; 10th National Meeting of Organic Chemistry, PC 71, 1st Luso-Brazilian Symposium of Organic Chemistry, September 2013, Lisbon, Portugal.

[12] Genin, E.; Hugues, V.; Clermont, G.; Herbivo, C.; Comel, A.; Castro, M. C. R.; Raposo, M. M. M.; Blanchard-Desce, M., Photochem. Photobiol. Sci., 2012, 11, 1756. 